\title{
Trust, Transparency and Welfare: Third-Sector Adult Social Care Delivery and the COVID-19 Pandemic in the UK
}

\author{
Paul Chaney * and Christala Sophocleous
}

check for

updates

Citation: Chaney, Paul, and Christala Sophocleous. 2021. Trust, Transparency and Welfare: Third-Sector Adult Social Care Delivery and the COVID-19 Pandemic in the UK. Journal of Risk and Financial Management 14: 572. https://doi.org/10.3390/ jrfm14120572

Academic Editor: Julien S. Baker

Received: 7 October 2021

Accepted: 11 November 2021

Published: 26 November 2021

Publisher's Note: MDPI stays neutral with regard to jurisdictional claims in published maps and institutional affiliations.

Copyright: (c) 2021 by the authors. Licensee MDPI, Basel, Switzerland. This article is an open access article distributed under the terms and conditions of the Creative Commons Attribution (CC BY) license (https:/ / creativecommons.org/licenses/by/ $4.0 /)$.
Wales Institute of Social and Economic Research, Data and Methods (WISERD), Cardiff University, Cardiff CF10 3AT, UK; SophocleousC1@cardiff.ac.uk

* Correspondence: chaneyp@cardiff.ac.uk

\begin{abstract}
Since the move to quasi-federalism in the 1990s, different territorial welfare mixes on adult social care (ASC) have emerged in the four nations of the UK. This study explores policy actors' views on their effectiveness in the pandemic with reference to the role of institutions, trust and transparency. The analysis is based on extensive secondary data analysis and primary interviews with key individuals involved in the delivery and regulation of ASC. The findings highlight how the pandemic exposed existing pathologies and the need for reform in all four systems. Notably, the analysis shows how the present market-based tendering systems for allocating ASC contracts undermine inter-personal and institutional trust and compromise care quality. The wider significance of this lies in showing the pivotal role of trust during the emergency and that post-pandemic welfare reform needs to embed trust-building measures to deliver effective care.
\end{abstract}

Keywords: pandemic; social welfare; trust; transparency; adult social care; UK

\section{Introduction}

Since the move to quasi-federalism, different territorial welfare mixes on adult social care delivery have emerged in the four nations of the UK. This study compares policy actors' views on their effectiveness in adult social care (ASC) delivery during the pandemic with reference to the role of institutions, trust and transparency. The analysis is based on extensive secondary data analysis and primary interviews with key individuals involved in the delivery and regulation of ASC. The term 'adult social care' refers to non-medical support, including provision of social work, personal care, protection or social support services, to adults in need, typically arising from old age and/or disability. Specifically, we examine domiciliary care in the service user's home (not in residential care homes). By "welfare mixes", we refer to the mixed economy of welfare-or welfare pluralism. Typically, local government social services departments issue contracts to provide ASC to local communities. Government policy determines the prevailing welfare mix. Care providers are either in the state sector (employed by local government), work for private sector companies operating for profit, or belong to not-for-profit bodies in the third (or voluntary) sector. Definitions of the latter are contested (cf. Salamon and Anheier 1998). For the present purposes, the third sector denotes charities, NGOs and co-operatives. It is also sometimes referred to as the community sector. Such organisations may deliver ASC through voluntary activities and/or they may secure state funding to supplement their voluntary service provision with paid employees.

It is germane to consider why the issue of ASC is deserving of attention. The answer is a major increase in demand for care due to an international demographic shift towards an ageing population. In the UK, the number of people $65+$ years is predicted to reach one-in-four people (24.2 per cent) by 2038 (ONS 2020). This global trend means we live in an era when, for first time in human history, the number of older people (60+ years) will exceed younger people. As a result of declining state capacity (owing to austerity, and latterly fiscal deficits incurred as part of the pandemic response), the UK Prime Minister 
has referred to a "crisis in social care". In consequence, third-sector adult care providers are increasingly in the front line of service providers for the vulnerable.

Against this backdrop, there is need for further scholarly work on the rise of mixed economies of welfare as a global phenomenon (Wigell 2017). Despite trust being a key variable in public support for state-organised welfare (Rose 1991; Rothstein 1998), to date, studies of social welfare have paid little attention to trust and multi-level governance (Daniele and Geys 2015). Moreover, the extant literature fails to take full account of how the mixed economy of welfare is grounded in the nature of political systems (Wigell 2017). In addition, classic welfare state theory (Esping-Andersen 1990; Arts and Gelissen 2002) tends to concentrate on state-wide practices, thereby overlooking the (increasing) significance of meso-level developments. As Daniele and Geys $(2015$, p. 3) observe, more work is needed on "the potential relevance for welfare state support of interpersonal trust among the members of a given community (over and above institutional trust)". While interpersonal trust has previously been linked to economic growth (Knack and Keefer 1997), financial development and international trade, its potential significance for welfare state support is limited. Dickinson et al. (2012, p. 24) concur: "Further research might also investigate the market niche that third-sector providers have in social care and examine how this is maintained, for example, through trust". There is also need for research on trust, welfare and inequalities. As Kevins (2019) underlines, the need to foster trust from welfare recipients that are labour-market outsiders (the majority of ASC users) is a particularly acute challenge as, typically, they exhibit lower levels of trust towards welfare providers.

Here, we engage with these lacunae and add to the current understanding of trust and the decentralization of the welfare state (Borghi and Van Berkel 2007; Chaney 2020a, 2020b). The present focus on meso-level developments is a corrective to the "methodological nationalism" of earlier state-wide research (Wimmer and Schiller 2002). It reflects the fact that the nature of prevailing welfare mixes is grounded in territorial electoral politics and political ideology (Chaney 2021). This matters because, as Henderson et al. (2013, p. 146) note, "[citizens] usually have more trust in regional than in national institutions". Today's quasi-federal UK can be viewed as a natural experiment in this regard. Lastly, whilst there is a literature on welfare delivery in the context of major emergencies, this is largely restricted to development studies. Here, we seek to extend this to consider the impact of the pandemic on ASC following the UK's move to multi-level governance.

The remainder of this paper is structured as follows. Following an outline of the study methodology, the findings are presented. These consider each territory in turn. First, the nature of the mixed economy model of ASC applying in each is outlined ("Research Context"), followed by examination of policy actors' views on the extent to which the four mixed economy models provided an effective response to ASC delivery in the pandemic, with reference to the role of trust and transparency ("Research Findings"). The discussion and conclusion reflect on the study findings and their implications.

\section{Methods}

This is a mixed methods study involving primary and secondary data analysis. In social theory terms, it uses qualitative discourse analysis because, as the interpretive school of policy analysis and social constructivism (Kukla 2000) underline, social research benefits from emphasis on values, beliefs, narratives and interpretations germane to a given policy issue (Eden and Ackermann 2004). Thus, it eschews quantification of interview responses and instead embraces standpoint theory. This is suited to exploring the "situated knowledge" (Stoetzler and Yuval-Davis 2002) of policy actors in relation to the delivery of social care before and during the pandemic. In this regard, it is methodologically concerned with the inherent meanings, messages and criticality in relation to social experience (Druckman 2001). It is allied to the classic work of Goffman (1974) and discursive framing or the language used by policy actors and the inherent meanings, sentiments, emotions, messages and criticality in relation to social and political communication (Heine and Narrog 2015). 
The primary data analysis comprised a sample of a hundred interviews with civil society policy actors and other stakeholders undertaken prior to, and during, the pandemic, 2017-2021. Purposive sampling was used to achieve a spread of interviewees, with a target of approximately 25 in each of the four nations (Godwill 2015; Campbell et al. 2020; Stratton 2021). The constraints of lockdown during the COVID-19 pandemic meant that the methodology was adapted from pre-COVID face-to-face data-gathering to online interviews during lockdown (via Zoom and similar digital platforms). The term "policy actors" here refers to those working for: third-sector organizations (TSOs) delivering domiciliary social care; bodies representing TSOs on regional partnership forums and other governance settings; and statutory commissions and inspectorates concerned with care standards, equality and human rights. The interviews that we secured were recorded and professionally transcribed. The transcripts were manually coded using deductive coding to identify emerging themes (Fereday and Muir-Cochrane 2006). As the burgeoning research methods literature attests (MacPhail et al. 2015; Saldaña 2021), manual coding was selected in preference to analytical software because it allows the researcher greater immersion in the dataset (Basit 2003; James 2013) and is often more accurate in understanding colloquial language use, as well as ambiguities, speaker emphasis and use of rhetorical devices, including irony (Mattimoe et al. 2021).

Following established methodological practice (see Natow 2020), the interview findings were triangulated with document analysis (Bowen 2009). The secondary data analysis involved exhaustive online keyword searches of parliamentary websites and those of CSOs and statutory regulators of ASC in the UK. Purposive sampling was again used to achieve documentary coverage across the four nations of the UK (Godwill 2015; Campbell et al. 2020). This rich dataset included extensive evidence submitted to a series of parliamentary inquiries on the response to the COVID-19 pandemic, such as the UK Parliament's Select Committee on Culture, Media and Sport inquiry on the impact of COVID-19 on the charity sector. Again, electronic versions of these documents were manually coded for emerging themes using Adobe Acrobat or the annotation tool for webpages in the Microsoft Edge web-browser (Mackieson et al. 2019).

\section{Research Context}

In this section, we succinctly outline the nature of the mixed economy model of ASC applying in each territory.

\subsection{Wales}

The Welsh mixed economy model of social care delivery is distinctive. Under Welsh law, specifically, the Social Services and Well-being (Wales) Act, 2014, local (or municipal) government is placed under a statutory duty to promote third-sector organisations' delivery of social care. From the outset, third-sector policy actors have highlighted the pivotal role of trust in their working with government. As one observed, "It wouldn't function without trust ... hard won, easily lost, isn't it?-trust". Despite the collectivist political aspiration of successive socialist/civic nationalist governments in Wales, a marketised, private sector dominated system endures. Two-thirds of ASC staff are in the in private (or "for profit") sector. The third and public sectors each employ 17 per cent of the ASC workforce (IFC Consulting 2018). This is unsurprising, as prior to devolution in 1999 Wales and England largely shared the same legal and policy framework (and, as we shall see below, English policy promoted private sector welfare delivery). Third-sector interviewees in the present study lauded the legislative approach of promoting third-sector ASC. However, they were also critical of 2014 Act. Far from promoting collectivism, they highlighted how it has led to marketisation and reinforced inequalities-not least, because of the "widespread use of spot contracts and brokerage systems" (Atkinson et al. 2016, p. 2). Policy actors refer to how these cause instability and uncertainty about third-sector ASC organisations' long-term survival. 


\subsection{Scotland}

A mixed-economy, marketised system of ASC operates in Scotland. Half of ASC staff are employed by third-sector organisations (the highest proportion in the UK). The remainder are in the public (23 per cent) and private sectors (31 per cent) (ICF 2018c). The current Scottish mixed economy model of ASC provision is set out in a complex raft of enactments that policy actors say tends to undermine transparency. Notably, the Community Care and Health (Scotland) Act 2002 introduced the totemic policy of "free" personal care for adults, regardless of income or whether they live at home or in residential care (in contrast to Wales and England where ASC is means-tested, and many have to pay for care). When related to the wider welfare literature, earlier work (e.g., Uslaner 2002) suggests that universal programmes might "increase trust by enhancing equality, optimism and the perception of individual opportunity" (Kevins 2019, p. 877). However, in part, the present findings contradict this premise. Policy actors were critical of several aspects of Scotland's mixed economy model. As Cunningham et al. (2019, p. 17) note, the Self-Directed Support (Scotland) Act (2013) (Scottish Parliament 2013) has promoted the marketization of care that has proved highly problematic for third-sector ASC providers. Many are critical of the commodification of ASC and the dehumanising language associated with it. One noted that, "We have reached a point where the commodification has in effect become the service. We have opted to put those services in place through a market mechanism which describes people's care and support arrangements as "packages"; we divide groups of people with support needs into "client groups" and bundle them into "lots", to be tendered on the market" (Coalition of Care and Support Providers in Scotland 2020, p. 3).

\subsection{Northern Ireland}

Northern Ireland also has a marketised system. Almost half of ASC workers are employed in the private sector. The public sector accounts for 30.1 per cent and the thirdsector 23 per cent (ICF 2018b). From an institutional perspective, the province of Northern Ireland is different to the other countries in the UK because social care is integrated into the public healthcare system. In common with Scotland, Northern Ireland has free-at-thepoint-of-delivery entitlement to personal care for adults regardless of income or whether they live at home or in residential care settings.

\subsection{England}

The nature of the mixed economy model of ASC in England is distinctive because of its neo-liberal approach. This is politically motivated-shaped by successive right-of-centre governments that eschew state provision and embrace contracting out to the private sector. In turn, this is reflected in the composition of the ASC workforce. Two-thirds of staff are employed in the private sector (64.8 per cent); just under a third are in the voluntary sector (31.9 per cent), whilst the public sector accounts for just 3.3 per cent (ICF 2018a). A recent review gave a withering critique of systemic ASC failings in England: "Short-term funding and the lack of a long-term vision has hampered planning, innovation and investment in adult social care. The current accountability and oversight arrangements are ineffective for overseeing the care market" (National Audit Office 2021, p. 6). Another concluded that major challenges stem from the complex and fragmented nature of the current system (Care Quality Commission 2019).

\section{Research Findings}

This section is structured to consider each territory in turn and examine policy actors' views on the response to ASC delivery in the pandemic.

\subsection{Wales}

The Welsh Government's pandemic response for third-sector ASC provision was included in a comprehensive emergency funding package for the sector as a whole. The official response also saw the relaxing of some bureaucratic rules on third-sector funding and 
service delivery. A key example of the emergency funding measures was the Third-Sector Resilience Fund, a blended loan and grant scheme designed to help third-sector organisations (TSOs) pay their bills and ease their cash-flow. Another was the Voluntary Services Emergency Fund, intended to enable more people to volunteer during the pandemic by coordinating the volunteer response and paying volunteers' out of pocket expenses.

The move to devolved government for Wales in the 1990s saw partnership working between government and third-sector embedded in constitutional law. During the pandemic, a government minister described this infrastructure as being "a huge positive". Policy actors also spoke of how, "successive Welsh Governments have invested in the third-sector and supported mechanisms for joint-working. It is notable that through the pandemic [ ... it] has continued to work through these existing structures, strengthening but not replacing them" (Welsh Parliament/Senedd Cymru 2021, p. 11). Third-sector policy actors also underlined the importance of the interpersonal and institutional trust built up through an extended history of working with meso-government. For example, one said: "for us that trust is a key thing. We have a lot of trust in the ... [Welsh Government] officials that we work with, because some of those relationships are going back a decade. So, each time you take on a new area of policy or new bit of work, we have to work a little bit less hard to establish trust". Policy actors also referred to how, "the voluntary sector played an invaluable role in sharing essential messages to communities and the people they support, particularly at the outset of the pandemic" (Welsh Parliament/Senedd Cymru 2021, para 47). Interviewees also spoke of how the third-sector provided local care (foodbanks, community transport, etc.) when state ASC provision was compromised by staff contracting COVID-19 and being hospitalised or self-isolating. The pandemic also saw a dramatic surge in volunteers keen to help in the emergency. However, reflecting wider international experience (Asmorowati et al. 2021), study participants highlight how a major shortcoming was the poor level of strategic co-ordination of volunteers. Policy actors also referred to the compounding of difficulties experienced during the pandemic because it coincided with a number of ongoing reform agendas, including health service reorganization and Brexit (many ASC providers lost employees as a result of Brexit, most noticeably from Eastern European counties). Notwithstanding these challenges, third-sector policy actors confirmed that, in the words of one, "a combination of the funding available from various governments has meant that many voluntary sector organisations have been able to "weather the storm'".

\subsection{Scotland}

One of the principal elements in the Scottish Government's pandemic response was a $£ 350$ million ( $\$ 484$ million) fund to support the welfare and wellbeing of those most affected by the coronavirus pandemic. This was open to local government, charities, businesses and community groups. Its aim was to "be focused on delivery, not bureaucracy or red tape". In consequence one policy actor reflected, "There has been more trust and less emphasis on reporting and monitoring, and we would really like that to continue". During the pandemic, additional funding was also added to the Scottish Welfare Fund (which makes community and crisis grants available to those in immediate need), the Food Fund (to help voluntary sector organisations address issues of food insecurity, especially for older people) and Wellbeing Fund (to help charities and others who require additional capacity to work with at-risk people who may be worst affected by the crisis).

In the wake of the pandemic, one third-sector leader reflected that, "Reform of social care in Scotland is long overdue. The COVID-19 pandemic has exposed fault lines which require radical overhaul and long-term change. It has also revealed what can be achieved when obstacles are removed in a crisis". Another questioned, "Can we use hard lessons learnt during COVID-19 to value social care more, and find new ways of supporting and valuing our most vulnerable citizens?" (SCVO 2020a, p. 5). Others referred to what they saw as problematic eligibility rules for the emergency aid. In particular, they complained that, under charities law, third-sector organisations relying on their reserves were not 
eligible for immediate crisis funding. They were only eligible when their funds were exhausted-effectively when they failed financially.

A common trope amongst policy actors was how the pandemic will drive future reform. For example, one parliamentarian said:

We must embrace the adversity of the pandemic and seize it as an opportunity to do things differently. We must learn from innovative practice shown by some funders and the third sector during the pandemic. The COVID crisis has shone a light on the issues impacting the sector and on inequality in our society.

Throughout, trust was a consistent theme. Notably, the Scottish Parliament's Report on the impact of the COVID-19 pandemic on equalities and human rights underlined the need for, "greater transparency and scrutiny of the changes to social care, including information on the criteria and tools used by public bodies in their decision-making, and what measures are being taken to ensure ongoing monitoring" (SPEHRC 2021, p. 28). Whilst the representative body of the third sector said: "the pandemic has exacerbated inequalities ... Confidence in voluntary sector services exists because of the work to nurture trusting relationships between the organisations and the people they work with. This allows the sector to gather lived experience to advocate for change, and these relationships also make the sector well-placed to work with those most disengaged and isolated" (SCVO 2020b, p. 10, para 53).

\subsection{Northern Ireland}

Policy actors are highly critical of the current situation in Northern Ireland. As one noted, "fundamental reform of adult care and support is required to avoid a total collapse of the system with all the implications this would have for those in need. This requires both leadership and ownership across the whole system of care and support". A key issue is that, in the words of one TSO manager, "the current mechanisms have not been successful in creating or enabling a mixed economy of service provision". A major failing is the way that the independent social care sector is struggling to recruit and retain staff. This is due to the low pay that ASC workers receive, with many leaving to take up posts in the hospitality and retail sectors of the economy. Whilst these typically offer low pay, it is often more than remuneration in social care. According to stakeholders, this is creating the "perfect storm" because it is combining with the negative effects of Brexit, austerity and decades of inequality and poverty.

Despite these difficulties, policy actors praised the response of third-sector ASC providers during the pandemic. As one put it, "the community sector came to the fore in ways that other sectors couldn't and wouldn't and I think the status of the community sector has been enhanced considerably ... they naturally stood up to the plate when lockdown came in and services were required. I mean, half, if not three-quarters of the public sector was at home" (i.e., incapacitated by COVID). They also highlighted the beneficial effects of government suspension of bureaucracy and red tape during the crisis. For example, one noted: "there was definitely an instant flexibility and rolling forward of funding arrangements for the next 12 months-you know, without too much scrutiny".

Reflecting on the impact of the pandemic on ASC, a government minister said: "it is important to continue this new way of working after Covid-19. Against the backdrop of a society that is facing increasing pressures compounded by the uncertainties presented of Brexit, a restrictive overall budget, decades of inequality and poverty, and poor mental health, it is important to continue the collaborative way of working demonstrated over the last few months". She proceeded to describe "three key pillars" under which she believes the current work can continue: partnership and collaboration, co-design and coproduction, and delivery of real improvements and real outcomes. Yet, when responding to the Northern Ireland Executive's pandemic recovery plan, third-sector policy actors said that the government needed to do more to address economic inequality and promote human rights in ASC (Northern Ireland Executive Department for Health 2020, pp. 9-12). 


\subsection{England}

The English pandemic response consisted of $£ 750$ million ( $\$ 1$ billion) of financial support for voluntary, community and social enterprises, including those delivering ASC. During the COVID emergency, a thousand third-sector organisations were surveyed by government. This revealed that almost half had accessed the government support packages. However, when asked about the effectiveness of the aid, almost half of respondents (43 per cent) gave negative replies (Department for Digital, Culture, Media and Sport and Office for Civil Society 2021). One TSO explained, "the Covid-19 crisis ... may tip over the charity. We are fighting hard to avoid this outcome [ ... we have suffered a] Loss of 70 per cent of our volunteers who are now self-isolating; and a loss of 90 per cent of our income over night".

Equalities and human rights organisations raised several concerns about the government's COVID response: "the government and public services must not use any new powers to undermine people's human rights and rights to equality and non-discrimination. The powers must be used in ways that are non-discriminatory and proportionate to achieving the legitimate aim of responding to the epidemic". The national representative body for third-sector organisations in England warned: "Charities across the country are facing imminent collapse as fundraising income dries up ... Community and voluntary sector organisations are also on the frontline of supporting vulnerable people and will experience a variety of impacts related to the crisis. Some are seeing huge increases in demand for services". For many care providers, survival was the key issue. One observed, "The crisis is biting us hard. Even with us doing everything we can (such as furloughing staff, applying for business support, paid staff voluntarily cutting their wages etc.). We will not be able to continue beyond the next few months if nothing substantial changes".

Others spoke of how, in their view, the pandemic response was compounding inequalities: "There is currently no clarity on what, if any, consideration will be given to equality and equity, including the need to fund organisations that represent marginalised communities. Poorer areas of the country ... feel the impacts of a reduction in services far more than wealthier parts of the country". This TSO concluded: "put simply, the government's intervention will not be enough to prevent good charities around the country from closing their doors. Many of the charities which do survive will look very different in a few months' time, with severely reduced capacity to provide support that people rely on at a time when their contribution to recovery will be vital".

(Mis)trust was a key issue in the marginalisation and inequalities experienced by black and minority ethnic (BAME) communities in England during the pandemic. Thus, a report by the state healthcare regulator called for improved access, experiences and outcomes of integrated care for black and minority ethnic communities. Recommended measures included, "integration of equality into quality systems; good representation of black and minority ethnic communities among staff at all levels [and] trust-building dialogue with service users" (Public Health England 2020, p. 10). Allied to this, one community leader told a government inquiry on the pandemic, "Muslim charities hold a great deal of trust with the communities they work with, but with rises in Islamophobia ... increased dialogue, communication and engagement with the Muslim charitable sector is recommended. During this unprecedented global crisis, it is imperative they are engaged with at the earliest possible time". Policy actors' discourse also reveals widespread anxiety that the organisations that support BAME groups may not survive due to the economic impact of the COVID-19 emergency. As one observer noted: "The prediction is that 40 per cent of SME community and voluntary sector will cease to exist in three months from now. Including those run by ethnic minorities supporting individuals with overlapping intersectionality (e.g., BAME, woman, single parent, mental illness, those not employed)these small organisations will cease to exist ... my concern is that trust is diminished yet again for these communities-but how do we sustain and strengthen a sector that doesn't exist?" (Public Health England 2020, p. 28). 


\section{Discussion: The Pandemic and the Role of Trust and Transparency in the Mixed Economy of ASC Delivery}

The current study reveals the pivotal role of trust in welfare delivery immediately prior to-and during, the pandemic. As one study participant noted 'It's huge, isn't it? If you haven't got trust, you haven't got open dialogue, you haven't got interest or understanding of each other's positions". Trust was seen as vital to policy development and co-working with government. For example, one interviewee said, "I think there is quite a good amount of trust and respect for our organisation from ... government officials. And particularly with one particular person that we work with. And I think we're often seen as the 'go to' organisation for our knowledge and skills on particular subjects ... they value our opinion and our reputation. And I think that there's a lot of trust and respect there". Across the four territories, the current analysis shows the main (non-discrete) dimensions of trust are institutional (between institutions, and citizens' trust towards institutions); intra-institutional (e.g., ASC workers' trust towards the organisations they work for) and inter-personal (i.e., between individuals spanning organisational boundaries, and between welfare service users and providers). Trust is also integral to the future success of postpandemic reforms, for as Habibov et al. (2019, p. 466) conclude: "welfare state reforms could prove be more effective within a social context where levels of trust are high. Thus, special attention should be paid to initiatives aimed at developing strategies to build trust".

In the case of institutional trust in the different territorial ASC systems in the UK, a key issue was how governance complexity undermines transparency and reduces trust on the part of third-sector organisations. As one interviewee put it "it's exposed more the need for trust and openness". A prime example is the complicated institutional structures associated with ASC delivery under the 2014 Act in Wales. This complexity has undermined the transparency of the system and, in turn, levels of third-sector trust in the new arrangements. The new institutional structures centre on Regional Partnership Boards (RPBs) designed to promote welfare pluralism and bring together state bodies, local government and the third-sector to meet the care and support needs of people in their area. In practice, the level of the third-sector's involvement in RPBs was found to be highly variable. In some areas, there was thorough-going engagement, yet in others non-engagement meant that thirdsector organisations were effectively excluded from shaping local ASC delivery. In such instances, RPBs effectively became a 'rubber stamping' exercise. Reasons for third-sector organisations' non-engagement included uncertainty about different institutional remits in relation to ASC delivery and a lack of resources and capacity to engage with the broad range of implementation structures.

The current analysis reveals a broadly similar situation in Scotland. The representative body of the third-sector concluded: "People in Scotland have grown ever more critical of those with decision-making power. Trust between policymakers and the public has fallen and continues to do so. With this growing mistrust and cynicism comes the need to find ways of opening up decision-making processes throughout the country, making them accessible and transparent for all" (SCVO 2020a, p. 3). Policy actors' discourse refers to policy complexity undermining trust, transparency and accountability. In response, during the pandemic the Scottish Government announced a review of ASC provision. Its vision for the successor system underlines a mixed-economy approach whereby, "People organising and delivering social care work together [including ... ] communities, community workers, mental health practitioners, GPs, nurses, hospitals, therapists, housing services, transport services, and others" (Scottish Government 2019, p. 14). The stated aim is for systems, processes and decision making where "the relationship between public, independent and third sector health and social care organisations is trusting and collaborative" (Scottish Government 2019, p. 14). The post-pandemic Independent Review of Social Care in Scotland also puts trust at the heart of its recommendations: "We also need a transformation of the way in which we plan, commission and procure social care support. We need an approach that builds trusting relationships rather than competition. We need to build partnerships not market-places" (Scottish Government 2021, p. 5). 
As earlier work emphasises, the degree of institutional trust depends on the perceived ability of institutions to deliver the expected outcomes (Wong et al. 2011; Habibov et al. 2019). The current study highlights two dimensions to trust in the pandemic response: government officials' attitudes towards community groups and citizens' attitudes towards government (as well as state, private and third-sector ASC providers). In the former regard, our analysis shows the need for state bodies to exhibit greater levels of trust towards third-sector organisations. As extant work (Van de Walle and Lahat 2017, p. 1450) observes, "given the critical role of trust in the functioning of the welfare state ... further awareness and mechanisms for increasing the degree of trust of citizens among public officials are warranted". The current evidence reveals that officials' willingness to trust community groups was shaped by the effectiveness of the pandemic response. Thus, a Parliamentary inquiry heard that: "Practical cooperation at community level was often good with local authorities; though [officials'] willingness to trust community groups has been very mixed. Pre-existing relationships (which contributed to levels of trust) were a major predictor of close working links during Lockdown. However, the crisis did help breakdown some of the pre-crisis barriers to co-operation such as poor communication, risk aversion and silo working, as people in both the statutory and voluntary sectors were driven overwhelmingly by the crisis to do things differently" (Welsh Parliament 2021, p. 23). Professionalism was a key factor determining officials' level of trust in community ASC providers. As one interviewee noted: "I mean, I think there is an overarching thing that I feel sometimes in the third-sector-[namely,] that the statutory bodies don't trust us enough to be a professional organisation. They just think, they have a particular image of volunteers which doesn't relate to the truth so there is always this perception inequality about things". Existing work (e.g., Taylor-Gooby 2000) has also underlined the links between welfare, risk and trust. This was evident in the current study findings-notably, when interviewees alluded to the role of evidence in boosting trust. For example, one third-sector policy actor spoke of government officials seeking prior evidence before extending funding to community groups for service delivery: "we've also got a capital programme, which government started funding about ten years ago. That was all about trust- that was about us showing a local project that worked [before we were given funding]".

Across polities, institutional trust is a core trope in the discourse on post-pandemic ASC reforms. For example, one third-sector body referred to: "encouraging an ongoing changing of behaviours and culture to share power better locally, regionally and nationally [this] will, I think, build that greater resilience." Others talked of "hard-wiring" key relationships between different organisations where necessary and ensuring that decision makers "truly trust their colleagues in their communities ..." . Such measures "are essential ... hard-wiring relationships would build resilience and mean that there can be improved responses" (Welsh Parliament 2021, p. 43). Another interviewee put it simply, "the process and the infrastructure for those relationships is based around trust".

A further common theme was how inter-personal trust between policy actors increased the longer the duration of the working relationship. Familiarity was seen as key to interpersonal trust, and interviewees gave a number of examples of how and when staff left their posts and how this impacted on prevailing levels of trust and, in turn, the efficacy of the working relationship. For example, one noted that "we are finding increasingly that we're dealing with different people all the time, and that doesn't support us in building trust and building a common understanding, and a common appreciation of knowledge and skill base, really". The current findings also reveal how staff retention issues during the pandemic negatively impacted on inter-personal trust between third-sector service care providers and service users. Those receiving ASC are often vulnerable and like the familiarity of the same carers (i.e., individuals) providing a service over time, which is something that builds inter-personal trust. However, care providers themselves were not immune from the virus. Associated illness, death and self-isolation amongst service providers had a major, disrupting influence, undermining interpersonal trust between service provider and client. The current findings also show that this had systemic causes owing to the 
marketised, tendering processes for ASC delivery in each of the four territorial welfare systems. As noted, these reward the lowest-cost tenders. In turn, this disincentivises care organisations from investing in staff training and career progression and encourages them to pay the minimum legal wage. In consequence, across polities, there is a major staff retention problem.

In liberal welfare states, the nature and extent of universal welfare provision may shape generalised trust with divides between welfare recipients and those who pay for them (Larsen 2007; Jensen and Svendsen 2011). The current study supports this and shows how, during the pandemic, citizen trust varied between different ASC providers in the different mixed economy models of care delivery. Notably, in England, the public trusted charities and voluntary sector providers to deliver social care more (60 per cent) than other organisations. Central government's role in ASC was trusted by only 7 per cent of respondents (Charities Aid Foundation 2020). Similarly, in Northern Ireland 71 per cent of respondents reported trusting charities in ASC delivery (12 per cent higher than in Great Britain, and 14 per cent higher than the Republic of Ireland, CCNI 2020). The Charity Commissioner for Northern Ireland said: "While I know many charities are struggling simply to survive in the unexpected world we're currently living in, it's important to remember just how vital the public are to charities - and the role that trust and confidence plays in running a successful charity, even during a pandemic. A charity that does not have the public's trust and confidence may find it struggles to raise funds, attract volunteers, staff and even beneficiaries, or simply cannot fulfil its charitable objectives" (CCNI 2020, p. 2). The qualities that the respondents identified as most likely to increase their trust and confidence included making a positive impact on the lives of beneficiaries, transparency and accountability, and operating ethically and honestly (CCNI 2020, p. 2).

\section{Conclusions}

Foremost of the current study findings is the policy-actors' view that the marketised, capitalist practices that allocate ASC contracts to the lowest-cost tenders fail to deliver the most effective welfare. As the foregoing reveals, such practices are also responsible for a series of trust pathologies. In this regard, there is another institutional trust issue that should be noted. It stems from the way the marketised, mixed economy systems force local third-sector and community organisations into competing with one another, rather than collaborating and pooling resources, knowledge and expertise. As one interviewee observed: "it creates difficulties in terms of trust, and it's not what we get commissioned for ... we have to be in a non-competitive place with our members. Being a service deliverer puts you immediately in a place of competition and that's not where any ... organisation should be".

At this juncture, it is appropriate to reflect upon this study's limitations and opportunities for future research. One limitation is that this study does not capture the full impact of the COVID-19 on the provision of ASC in the community. Rather, it provides needed analysis of the emergence of the pandemic and its initial impact through to late-2021. At the time of writing (circa November 2021), the pandemic was ongoing in the UK (with 43,000 new cases of people contracting Coronavirus and 217 deaths recorded in the past twenty-four hours). Future research will be needed to assess the longer-term impact of this global health emergency. Furthermore, we have deliberately concentrated on the situated knowledge of policy actors, notably, managers and workers with third-sector organisations. Further work is needed to explore and understand the views and experiences of those receiving social care. Their views will also be of vital importance in building future resilience against new health emergencies that may emerge over the coming years. Lastly, we have deliberately adopted a social constructivist and interpretivist epistemology-operationalized through qualitative research methods that draw on the situated knowledge of policy actors. As noted, the reason for this is to let these individuals "speak" to us at a critical juncture in modern history with direct quotations from their accounts of the pandemic. Future work will usefully complement this with quantitative survey data and panel studies. 
Overall, the present study's findings suggest the need for more interventionist measures to boost trust in order to deliver higher-quality adult social care in the face of ever-increasing demand. In this regard, there is some evidence that this message is beginning to be taken seriously by politicians and policymakers. For example, according to the Expert Advisory Panel's Proposals to reboot adult care and support in Northern Ireland (Kelly and Kennedy 2017, p. 64), trust and transparency need to be at the heart of a reformed system: "There is a lack of honesty and transparency created by an arms-length commissioning system which is unsuited for the imperfect market that exists in care and support services. It is not the same as procuring stationery or roads maintenance. Care and support involve supporting a human environment and culture that encourages relationships and kindness. The market we create needs to recognise this". Notably, the Scottish discourse also makes the case for addressing these issues through a formal statement of principles—or 'social covenant' - to shape post-pandemic reform: "One key factor is the need for mutual commitment by citizens, representative bodies, providers, civic Scotland, and national government to set aside self-interest and each work together for the common good. Trust is not currently in plentiful supply in social care support and so we believe that there is a need for an explicit social covenant to which all parties would sign up. This will be particularly important if we want to achieve our aspiration for everyone in Scotland to get the social care support they need to live their lives as they choose and to be active citizens" (Scottish Government 2021, p. 13). Whether such measures are part of future ASC reforms will ultimately be determined not by political rhetoric but by the economic necessities of a historically unprecedented post-pandemic fiscal deficit and whether voters are willing to pay the higher taxes such reforms may entail. Past experience does not bode well in this regard.

Author Contributions: Conceptualization, methodology, validation, formal analysis, investigation, resources, data curation, writing_-original draft preparation/writing—review and editing, visualization, supervision, project administration-P.C. and C.S. All authors have read and agreed to the published version of the manuscript.

Funding: This research was funded by the Economic and Social Research Council (ESRC), grant number ES/S012435/1. The APC was funded by Hong Kong Baptist University.

Institutional Review Board Statement: The study was conducted according to the guidelines of the Declaration of Helsinki and approved by the Ethics Committee of the School of Social Sciences, Cardiff University. (Protocol code SREC/3417 and 31 January 2017).

Informed Consent Statement: Informed consent was obtained from all subjects involved in the study.

Data Availability Statement: Data supporting reported results will be deposited with the ESRC data archive https: / /www.data-archive.ac.uk/ (accessed 5 November 2021).

Acknowledgments: The authors are indebted to the editors and three anonymous referees for their helpful and constructive feedback and suggestions on an earlier draft of this paper.

Conflicts of Interest: The authors declare no conflict of interest.

\section{References}

Arts, Wil, and John Gelissen. 2002. Three worlds of welfare capitalism or more? A state-of-the-art report. Journal of European Social Policy 12: 137-56. [CrossRef]

Asmorowati, Sulikah, Violeta Schubert, and Ayu Puspita Ningrum. 2021. Policy capacity, local autonomy, and human agency: Tensions in the intergovernmental coordination in Indonesia's social welfare response amid the COVID-19 pandemic. Journal of Asian Public Policy, 1-15. [CrossRef]

Atkinson, Carol, Sarah Crozier, and Elizabeth Lewis. 2016. Factors that Affect the Recruitment and Retention of Domiciliary Care Workers and the Extent to Which These Factors Impact Upon the Quality of Domiciliary Care. Cardiff: Welsh Government.

Basit, Tehmina. 2003. Manual or electronic? The role of coding in qualitative data analysis. Educational Research 45: 143-54. [CrossRef]

Borghi, Vando, and Rik Van Berkel. 2007. New Modes of Governance in Italy and the Netherlands: The Case of Activation Policies. Public Administration 85: 83-101. [CrossRef]

Bowen, Glenn A. 2009. Document Analysis as a Qualitative Research Method. Qualitative Research Journal 9: 27-40. [CrossRef] 
Campbell, Steve, Melanie Greenwood, Sarah Prior, Toniele Shearer, Kerrie Walkem, Sarah Young, Danielle Bywaters, and Kim Walker. 2020. Purposive sampling: Complex or simple? Research case examples. Journal of research in Nursing 25: 652-61. [CrossRef]

Care Quality Commission. 2019. The State of Health Care and Adult Social Care in England 2018/19. Newcastle: Care Quality Commission.

Chaney, Paul. 2020a. Human Rights and Social Welfare Pathologies: Civil Society Perspectives on Contemporary Practice across UK Jurisdictions. International Journal of Human Rights 25: 639-74. [CrossRef]

Chaney, Paul. 2020b. Examining Political Parties' Record on Refugees and Asylum Seekers in UK Party Manifestos 1964-2019: The Rise of Territorial Approaches to Welfare? Journal of Immigrant $\mathcal{E}$ Refugee Studies 19: 488-510.

Chaney, Paul. 2021. Exploring the Politicisation and Territorialisation of Adult Social Care in the UK: Electoral Discourse Analysis of State-wide and Meso Elections 1998-2019. Global Social Policy. [CrossRef]

Charities Aid Foundation. 2020. Giving Civil Society the Right Response: National Policy Responses for Supporting Philanthropy, Giving and Civil Society across the World in the Context of COVID-19. London: CAF.

Charity Commission of Northern Ireland. 2020. NICVA COVID-19 Impact Survey 2020. Belfast: CCNI.

Coalition of Care and Support Providers in Scotland. 2020. Independent Review of Adult Social Care, Submission from CCPS-Coalition of Care E Support Providers in Scotland. Edinburgh: CCPS.

Cunningham, Ian, Alina Baluch, Philip James, Eva Jendro, and Douglas Young. 2019. Handing Back Contracts: Exploring the Rising Trend in Third Sector Provider Withdrawal from the Social Care Market. Edinburgh: CCPS/University of Strathclyde Business School.

Daniele, Gianmarco, and Benny Geys. 2015. Interpersonal trust and welfare state support. European Journal of Political Economy 39: 1-12. [CrossRef]

Department for Digital, Culture, Media and Sport and Office for Civil Society. 2021. Investigation into Government Funding to Charities during the COVID-19 Pandemic. London: DCMS.

Dickinson, Helen, Kerry Allen, Pete Alcock, Rob Macmillan, and Jon Glasby. 2012. The Role of the Third Sector in Delivering Social Care. London: National Institute for Health Research.

Druckman, James. 2001. The implications of framing effects for citizen competence. Political Behavior 23: 225-56. [CrossRef]

Eden, Colin, and Fran Ackermann. 2004. Cognitive Mapping Expert Views for Policy Analysis in the Public Sector. European Journal of Operational Research 152: 615-30. [CrossRef]

Esping-Andersen, Gosta. 1990. The Three Worlds of Welfare Capitalism. Princeton: Princeton University Press.

Fereday, Jennifer, and Eimear Muir-Cochrane. 2006. Demonstrating Rigor Using Thematic Analysis: A Hybrid Approach of Inductive and Deductive Coding and Theme Development. International Journal of Qualitative Methods 5: 80-92. [CrossRef]

Godwill, Engwa A. 2015. Fundamentals of Research Methodology: A Holistic Guide for Research Completion, Management, Validation and Ethics. New York: Nova Publishers.

Goffman, Erving. 1974. Frame Analysis. Cambridge: Harvard University Press.

Habibov, Nazim, Alena Auchynnikava, Rong Luo, and Lida Fan. 2019. Influence of interpersonal and institutional trusts on welfare state support revisited: Evidence from 27 post-communist nations. The International Journal of Sociology and Social Policy 39: 644-60. [CrossRef]

Heine, Bernd, and Heiko Narrog. 2015. The Oxford Handbook of Linguistic Analysis, 2nd ed. Oxford: Oxford University Press.

Henderson, Ailsa, Charlie Jeffery, Daniel Wincott, and Richard Wyn Jones. 2013. Reflections on the "devolution paradox": A comparative examination of multilevel citizenship. Regional Studies 47: 303-22. [CrossRef]

ICF. 2018a. The Economic Value of the Adult Social Care Sector-England: Final Report. London: ICF.

ICF. 2018b. The Economic Value of the Adult Social Care Sector-Northern Ireland: Final Report. London: ICF.

ICF. 2018c. The Economic Value of the Adult Social Care Sector-Scotland: Final Report. London: ICF.

IFC Consulting. 2018. The Economic Value of the Adult Social Care Sector-Wales, Final Report. London: IFC.

James, Allison. 2013. Seeking the analytic imagination: Reflections on the process of interpreting qualitative data. Qualitative Research 13: 562-77. [CrossRef]

Jensen, Carsten, and Gert Tinggaard Svendsen. 2011. Giving money to strangers: European welfare states and social trust. International Journal of Social Welfare 20: 3-9. [CrossRef]

Kelly, Des, and John Kennedy. 2017. Power to the People, Proposals to Reboot Adult Care E Support in Northern Ireland. Belfast: Expert Advisory Panel on Adult Care and Support.

Kevins, Anthony. 2019. Dualized trust: Risk, social trust and the welfare state. Socio-Economic Review 17: 875-97. [CrossRef]

Knack, Stephen, and Philip Keefer. 1997. Does social capital have an economic payoff? A cross-country investigation. Quarterly Journal of Economics 112: 1251-88. [CrossRef]

Kukla, André. 2000. Social Constructivism and the Philosophy of Science. London: Routledge.

Larsen, Christian. 2007. How Welfare Regimes Generate and Erode Social Capital: The Impact of Underclass Phenomena. Comparative Politics 40: 83-101. [CrossRef]

Mackieson, Penny, Aron Shlonsky, and Marie Connolly. 2019. Increasing rigor and reducing bias in qualitative research: A document analysis of parliamentary debates using applied thematic analysis. Qualitative Social Work 18: 965-80. [CrossRef]

MacPhail, Catherine, Nomhle Khoza, Laurie Abler, and Meghna Ranganathan. 2015. Process guidelines for establishing Intercoder Reliability in qualitative studies. Qualitative Research 16: 198-212. [CrossRef]

Mattimoe, Ruth, Michael T. Hayden, Brid Murphy, and Joan Ballantine. 2021. Approaches to Analysis of Qualitative Research Data: A Reflection on the Manual and Technological Approaches. Accounting, Finance, E Governance Review 27: 54-69. 
National Audit Office. 2021. The Adult Social Care Market in England. London: NAO.

Natow, Rebecca S. 2020. The use of triangulation in qualitative studies employing elite interviews. Qualitative Research $20:$ 160-73. [CrossRef]

Northern Ireland Executive Department for Health. 2020. Department of Health-Temporary Amendment of the Health and Social Care Framework Document for the Period June 2020 to May 2022: Consultation Document. Belfast: Northern Ireland Executive Department for Health.

Office for National Statistics. 2020. Population Estimates for the UK, England and Wales, Scotland and Northern Ireland, Provisional: Mid-2019. Newport: ONS.

Public Health England. 2020. Beyond the Data: Understanding the Impact of COVID-19 on BAME Groups. London: PHE.

Rose, Richard. 1991. Is American public policy exceptional? In Is America Different? A New Look at American Exceptionalism. Edited by Bercovitch E. Shafer. Oxford: Clarendon Press.

Rothstein, Bo. 1998. Just Institutions Matter: The Moral and Political Logic of the Universal Welfare State. Cambridge: Cambridge University Press.

Salamon, Lester M., and Helmut K. Anheier. 1998. Social Origins of Civil Society: Explaining the Nonprofit Sector Cross-Nationally. VOLUNTAS: International Journal of Voluntary and Nonprofit Organizations 9: 213-48. [CrossRef]

Saldaña, Johnny. 2021. The Coding Manual for Qualitative Researchers, 4th ed. Los Angeles and London: SAGE Publications Ltd.

Scottish Council for Voluntary Organization (SCVO). 2020a. Manifesto for the Future: A Summary of the SCVO Policy Forum's Blueprint for Scotland. Edinburgh: SCVO.

Scottish Council for Voluntary Organization (SCVO). 2020b. Submission to the House of Lords: Lessons from Coronavirus. Edinburgh: SCVO.

Scottish Government. 2019. Social Care Support: An Investment in Scotland's People, Society, and Economy-Programme Framework, A Partnership Programme to Support Local Reform of Adult Social Care. Edinburgh: Scottish Government.

Scottish Government. 2021. Independent Review of Adult Social Care in Scotland; Edinburgh: Scottish Government.

Scottish Parliament Equality and Human Rights Committee. 2021. Report on the Impact of the COVID-19 Pandemic on Equalities and Human Rights. Edinburgh: Scottish Parliament.

Scottish Parliament. 2013. Self-Directed Support (Scotland) Act (2013). Edinburgh: Scottish Parliament.

Stoetzler, Marcel, and Nira Yuval-Davis. 2002. Standpoint Theory, Situated Knowledge and the Situated Imagination. Feminist Theory 3: 315-33. [CrossRef]

Stratton, Samuel J. 2021. Population Research: Convenience Sampling Strategies. Prehospital and disaster Medicine 36: 373-74. [CrossRef]

Taylor-Gooby, Peter, ed. 2000. Risk, Trust and Welfare. Basingstoke: Palgrave Macmillan.

Uslaner, Eric M. 2002. The Moral Foundations of Trust. Cambridge: Cambridge University Press.

Van de Walle, Steven, and Lihi Lahat. 2017. Do Public Officials Trust Citizens? A Welfare State Perspective. Social Policy E Administration 51: 1450-69.

Welsh Parliament. 2021. Equality, Local Government and Communities Committee: Review of the Impact of Covid-19 on the Voluntary Sector. Cardiff: Welsh Parliament.

Welsh Parliament/Senedd Cymru. 2021. Health, Social Care and Sport Committee Inquiry into the Impact of the Covid-19 Outbreak, and Its Management, on Health and Social care in Wales. Cardiff: Welsh Parliament/Senedd Cymru.

Wigell, Mikael. 2017. Political Effects of Welfare Pluralism: Comparative Evidence from Argentina and Chile. World Development 95: 27-42. [CrossRef]

Wimmer, Andreas, and Nina Glick Schiller. 2002. Methodological nationalism and beyond: Nation-State building, migration and the social sciences. Global Networks 2: 301-34. [CrossRef]

Wong, Timothy Ka-ying, Po-san Wan, and Hsin-Huang Michael Hsiao. 2011. The bases of political trust in six Asian societies: Institutional and cultural explanations compared. International Political Science Review 32: 263-81. [CrossRef] 